NOTICE: this is the author's version of a work that was accepted for publication in <Structures>. Changes resulting from the publishing process, such as peer review, editing, corrections, structural formatting, and other quality control mechanisms may not be reflected in this document. Changes may have been made to this work since it was submitted for publication. A definitive version was subsequently published in STRUCTURES, [VOL 2, (JUNE 2015)] DOI 10.1016/j.istruc.2015.02.003

\title{
Effective width equations accounting for element interaction for cold- formed stainless steel square and rectangular hollow sections
}

\author{
Bock $\mathrm{M}^{*}$ and Real E \\ Department of Construction Engineering, Universitat Politècnica de Catalunya, UPC \\ C/ Jordi Girona, 1-3. 08034 Barcelona, Spain \\ * Corresponding author: Tel: +0034 934054156, Fax: +0034 934054135, e-mail: \\ marina.bock@upc.edu
}

\begin{abstract}
Rectangular hollow sections featuring high height-to-width (aspect) ratios have shown to offer improved ultimate capacity due to the effects of the interaction between the elements within the cross-section which are particularly significant for slender cross-sections (class 4) undergoing local buckling. The European design rules dealing with stainless steel, EN 19931-4 [1], utilises the concept of cross-section classification and the effective width method for the design of slender cross-sections susceptible to local buckling neglecting such interaction effects, hence resulting in conservative predictions. This paper examines the benefits of element interaction effects on cold-formed ferritic stainless steel compressed sections on the basis of carefully validated finite element models. Following parametric studies, the applicability of various alternative design approaches accounting for element interaction to ferritic stainless steel is assessed and effective width curves, as well as a Class 3 limiting slenderness equation, are derived herein as an explicit function of the aspect ratio. Comparisons with the loads achieved in the FE models have shown that the proposed effective width equations allowing for the benefits of element interaction improve capacity predictions making design more cost-effective.
\end{abstract}

\section{Highlights:}

- Numerical modelling of cold-formed ferritic stainless steel stub columns.

- Study of the influence of some key parameters on the numerical response.

- Successful validation of the scope of various methods to cover ferritic steel.

- Incorporation of element interaction effects into the effective width formulation.

- Reliability analysis and validation of the proposed method against existing tests.

Keywords: cold-formed, effective width equation, element interaction, numerical modelling, local buckling, slender cross-sections, slenderness limits, stainless steel

\section{Introduction}

The increased material price of stainless steel has always discouraged its use in the construction industry. However, stainless steel's favourable properties may result in decreased expenditure through its life provided they are designed efficiently [2]. Thereby, a better understanding of their structural behaviour is essential to use stainless steel more wisely. Structural research programmes conducted across the world have caused a significant impact on usage of stainless steel in construction and design guidance development [3]. Notable experimental studies concerning local buckling response of hollow sections include [4-6] covering austenitic stainless steel and [7, 8] on high-strength stainless steel (highstrength austenitic and duplex stainless steel) among others. The nickel content of these 
grades, however, particularly affects their costs which lead to the investigation of more pricestable alternatives such as lean duplex grades [9] and ferritic grades [10]. The structural applications of this latter type of stainless steel have been recently investigated within a European Project framework and comprehensive design guidance for construction applications has been developed [11]. For the local buckling proposed design provisions, which were firstly based on numerical analyses [12, 13], experimental research [14] was undertaken to provide further verification and is presented hereafter.

The purpose of this paper is to investigate the element interaction effects on cold-formed ferritic stainless steel sections comprising slender elements in compression. The sections taken into account were square and rectangular hollow sections (SHS and RHS, respectively). Owing to the cross-sectional shape of the former and when subjected to uniform compression, the four constituent plate elements are equally restrained to one another and simply supported conditions can be assumed at the interconnected boundaries between these plates. However, in a uniformly compressed RHS, the two short plate elements provide additional edge restraints to the longer elements and the boundary conditions tend towards fixed supports as the aspect ratio increases. These element interaction effects result in improved compression capacity and are particularly significant in RHS comprising slender elements. The benefits of such additional restraints are examined herein numerically by using the finite element model (FE) package ABAQUS. The results were used to assess the suitability and performance of various design methods that were developed or used for carbon steel and/or other stainless steel to ferritic stainless steel. These include the classic effective width method and Class 3 slenderness limit given in EN 1993-1-4 [1] and those revised by Gardner and Theofanous [15], which neglect such interaction effects, as well as alternative design approaches that account for element interaction. For these latter methods, the Direct Strength Method (DSM) [16] developed by Schafer and adapted for stainless steel by Becque et al. [17], the regression analysis method proposed by Kato [18] and modified by Theofanous and Gardner [19], and the effective cross-section method proposed by Zhou et al. [20] were considered. One additional design approach worthy of mention, but not detailed here further as its potential is exploited for more complex cross-sections than those considered herein, is the Generalised Beam Theory (GBT) pioneered by Schardt in Germany [21], extended by Davies in Britain [22,23] and actively upgraded over the last years by Camotim and his colleagues in Portugal [24,25].

Finally, a modification is proposed so that the effective width method accounts for the benefits of element interaction by inserting the aspect ratio within both the reduction factor $\rho$ equation and the Class 3 limiting slenderness value. The proposed amendment is statistically validated following the guidelines given in Annex D of EN 1990 [26] and compared with existing test results to verify its applicability to all stainless steel families.

\section{Numerical investigation}

\subsection{Modelled stub column tests}

In order to numerically investigate the benefits of element interaction effects on ferritic stainless steel slender sections, and because of the limited available experimental data on the performance of this type of cross-sections, only the experimental investigation conducted by the authors on cold-formed ferritic stainless steel slender sections [14] is considered herein to develop and validate a comprehensive FE model using the FE package ABAQUS. Bock et al. [14] reported the results of 8 stub column tests performed on 4 different SHS and RHS (two repeated tests on each cross-section), including the measurements of such geometries and initial local imperfections $\mathrm{w}_{0}$, as given in Table 1 where $\mathrm{L}$ is the length of the specimen, $\mathrm{H}$ is 
the overall height, $\mathrm{B}$ is the overall width, $t$ is the thickness, $r_{i}$ is the internal corner radius, $\alpha$ is the aspect ratio and $\mathrm{A}$ is the gross cross-sectional area (see Fig. 1). Note that these tests were particularly suitable to validate the FE model owing to the various aspect ratios of the specimens.

Table 1. Measured dimensions and test results [14]

\begin{tabular}{|c|c|c|c|c|c|c|c|c|c|c|c|}
\hline Specimen & $\begin{array}{c}\mathrm{L} \\
(\mathrm{mm})\end{array}$ & $\begin{array}{c}\mathrm{H} \\
(\mathrm{mm})\end{array}$ & $\begin{array}{c}\mathrm{B} \\
(\mathrm{mm})\end{array}$ & $\begin{array}{c}\mathrm{t} \\
(\mathrm{mm})\end{array}$ & $\begin{array}{c}\mathrm{R} \\
(\mathrm{mm})\end{array}$ & $\begin{array}{c}r_{i} \\
(\mathrm{~mm})\end{array}$ & $\begin{array}{c}\mathrm{A} \\
\left(\mathrm{mm}^{2}\right)\end{array}$ & $\alpha$ & $\begin{array}{c}\mathrm{w}_{0} \\
(\mathrm{~mm})\end{array}$ & $\begin{array}{l}\mathrm{N}_{\mathrm{u}, \text { tests }} \\
(\mathrm{kN})\end{array}$ & $\begin{array}{c}\delta_{\mathrm{u}} \\
(\mathrm{mm})\end{array}$ \\
\hline $60 \times 60 \times 2-S C 1$ & 179.5 & 60.3 & 60.3 & 2.00 & 4.4 & 2.4 & 454 & 1 & 0.02 & 211.37 & 1.02 \\
\hline $60 \times 60 \times 2-S C 2$ & 180.0 & 60.3 & 60.4 & 2.02 & 4.4 & 2.3 & 460 & 1 & 0.02 & 212.31 & 1.03 \\
\hline $70 \times 50 \times 2-S C 1$ & 210.0 & 70.1 & 49.9 & 2.00 & 4.3 & 2.3 & 451 & 1.4 & 0.03 & 190.15 & 0.87 \\
\hline $70 \times 50 \times 2-S C 2$ & 210.0 & 70.0 & 49.8 & 1.99 & 4.2 & 2.2 & 450 & 1.4 & 0.03 & 190.05 & 0.84 \\
\hline $80 \times 40 \times 2-S C 1$ & 240.0 & 80.0 & 40.5 & 2.00 & 3.3 & 1.3 & 457 & 2 & 0.06 & 178.21 & 0.80 \\
\hline $80 \times 40 \times 2-S C 2$ & 240.0 & 80.0 & 40.3 & 1.99 & 3.9 & 1.9 & 453 & 2 & 0.06 & 179.52 & 0.82 \\
\hline $100 \times 40 \times 2-S C 1$ & 299.5 & 100.1 & 40.0 & 2.05 & 4.1 & 2.1 & 546 & 2.5 & 0.07 & 184.23 & 0.97 \\
\hline $100 \times 40 \times 2-S C 2$ & 299.5 & 100.1 & 40.5 & 1.99 & 4.2 & 2.2 & 532 & 2.5 & 0.07 & 183.99 & 0.92 \\
\hline
\end{tabular}

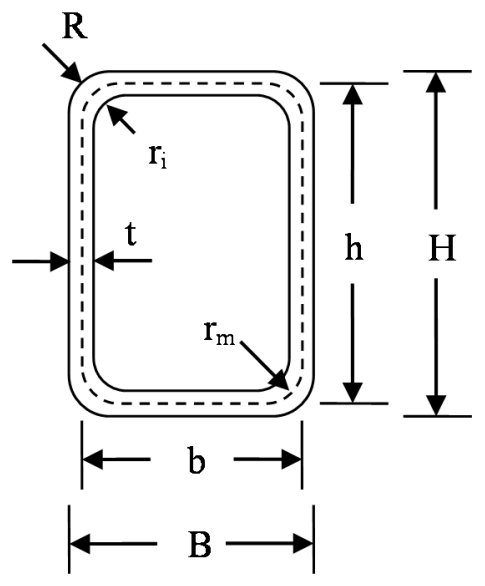

Fig. 1 Definition of symbols

Material properties were derived from coupon tests in [14], including tensile flat and corner coupons. The formers were extracted from flat faces of the specimens whereas the latter were taken from the curved portions of each of the cross-sections to quantify the corner strength enhancements induced by the cold-forming process [27].

Experimental observations in the corner regions [28] concluded that this enhanced strength extends into the flat regions by a distance equal to two times the material thickness. This remark has been used in previous numerical studies on other stainless steel grades $[29,30]$ and adopted herein. Measurements of residual stresses were not explicitly taken in [14] since they are inherently present (i.e. through-thickness residual stresses) in material properties extracted from cold-formed sections [4] and have shown little influence on the cross-sectional response [31]. The material properties determined in [14] are summarised in Table 2 for the four sections where the reported parameters are the Young's modulus E, the $0.01 \%, 0.05 \%$ and $0.2 \%$ proof stress $\sigma_{0.01}, \sigma_{0.05}$ and $\sigma_{0.2}$, respectively, and the ultimate stress $\sigma_{\mathrm{u}}$ with its corresponding ultimate strain $\varepsilon_{\mathrm{u}}$. Table 3 gives the weighted average values based on face width and corner properties extended two times the thickness through the flat region for all the tested specimens while Table 4 shows the average material properties of all the flat and corner tensile coupon tests. These sets of material properties are used in the following sections to assess their influence on the numerical response. 
Table 2. Measured material properties for the sections [14]

\begin{tabular}{|c|c|c|c|c|c|c|c|}
\hline Section & Portion & $\begin{array}{c}\mathrm{E} \\
(\mathrm{Gpa})\end{array}$ & $\begin{array}{c}\sigma_{0.01} \\
(\mathrm{MPa})\end{array}$ & $\begin{array}{c}\sigma_{0.05} \\
(\mathrm{MPa})\end{array}$ & $\begin{array}{c}\sigma_{0.2} \\
(\mathrm{MPa})\end{array}$ & $\begin{array}{c}\sigma_{\mathrm{u}} \\
(\mathrm{MPa})\end{array}$ & $\varepsilon_{\mathrm{u}}$ \\
\hline \multirow{2}{*}{ SHS $60 \times 60 \times 2$} & Flat & 167 & 327 & 389 & 431 & 478 & 0.111 \\
\hline & Corner & 167 & 360 & 471 & 548 & 568 & 0.008 \\
\hline \multirow{2}{*}{ RHS $70 \times 50 \times 2$} & Flat & 176 & 324 & 380 & 419 & 480 & 0.138 \\
\hline & Corner & 179 & 382 & 484 & 555 & 574 & 0.012 \\
\hline \multirow{2}{*}{ RHS $80 \times 40 \times 2$} & Flat & 177 & 326 & 381 & 418 & 485 & 0.143 \\
\hline & Corner & 181 & 380 & 474 & 572 & 595 & 0.008 \\
\hline \multirow{2}{*}{ RHS $100 \times 40 \times 2$} & Flat & 178 & 333 & 384 & 416 & 483 & 0.133 \\
\hline & Corner & 180 & 371 & 463 & 553 & 579 & 0.001 \\
\hline
\end{tabular}

Table 3. Weighted average tensile material properties [14]

\begin{tabular}{ccccccc}
\hline Specimen & $\begin{array}{c}\mathrm{E} \\
(\mathrm{Gpa})\end{array}$ & $\begin{array}{c}\sigma_{0.01} \\
(\mathrm{MPa})\end{array}$ & $\begin{array}{c}\sigma_{0.05} \\
(\mathrm{MPa})\end{array}$ & $\begin{array}{c}\sigma_{0.2} \\
(\mathrm{MPa})\end{array}$ & $\begin{array}{c}\sigma_{\mathrm{u}} \\
(\mathrm{MPa})\end{array}$ & $\varepsilon_{\mathrm{u}}$ \\
\hline $60 \times 60 \times 2-\mathrm{SC} 1$ & 167 & 335 & 409 & 458 & 499 & 0.087 \\
$60 \times 60 \times 2-\mathrm{SC} 2$ & 167 & 335 & 409 & 458 & 499 & 0.087 \\
$70 \times 50 \times 2-\mathrm{SC} 1$ & 176 & 337 & 404 & 450 & 502 & 0.108 \\
$70 \times 50 \times 2-\mathrm{SC} 2$ & 176 & 337 & 404 & 450 & 501 & 0.109 \\
$80 \times 40 \times 2-\mathrm{SC} 1$ & 177 & 338 & 399 & 449 & 507 & 0.116 \\
$80 \times 40 \times 2-\mathrm{SC} 2$ & 177 & 339 & 399 & 452 & 509 & 0.113 \\
$100 \times 40 \times 2-S C 1$ & 178 & 340 & 399 & 443 & 502 & 0.109 \\
$100 \times 40 \times 2-S C 2$ & 178 & 341 & 399 & 442 & 501 & 0.109 \\
\hline
\end{tabular}

Table 4. Average material properties based on all tensile coupons for the portions

\begin{tabular}{ccccccc}
\hline Portion & $\begin{array}{c}\mathrm{E} \\
(\mathrm{Gpa})\end{array}$ & $\begin{array}{c}\sigma_{0.01} \\
(\mathrm{MPa})\end{array}$ & $\begin{array}{c}\sigma_{0.05} \\
(\mathrm{MPa})\end{array}$ & $\begin{array}{c}\sigma_{0.2} \\
(\mathrm{MPa})\end{array}$ & $\begin{array}{c}\sigma_{\mathrm{u}} \\
(\mathrm{MPa})\end{array}$ & $\varepsilon_{\mathrm{u}}$ \\
\hline Flat & 174 & 328 & 383 & 421 & 481 & 0.131 \\
Corner & 177 & 373 & 473 & 557 & 579 & 0.009 \\
\hline
\end{tabular}

All the specimens were uniformly compressed between flat platens in an Instron $1000 \mathrm{kN}$ hydraulic testing machine which was driven by displacement control. The achieved test load $\mathrm{N}_{\mathrm{u} \text {,test }}$ and its corresponding specimen's end shortening $\delta_{\mathrm{u}}$ are given in Table 1.

\subsection{Finite element model}

The FE analysis package ABAQUS was used to simulate the cross-sectional response of the 8 ferritic stainless steel compression SHS and RHS tested in [14]. The measured geometric properties given in Table 1 were used in the FE model, which was based on the centreline dimensions of the cross-sections $\mathrm{h} \times \mathrm{b} \times \mathrm{r}_{\mathrm{m}}$ (see Fig. 1). The geometry of all the specimens was discretized using the four-node general-purpose shell element with reduced integration S4R $[32,33]$, including both flat parts and curved regions of the cross-sections. The geometry of these latter regions was approximated by 3 linear elements. The flat regions adjacent on either side of the corners, which are affected by the cold-forming process exhibiting enhanced strength, were discretized using two elements, each of them with size equal to the thickness of the cross-section. For the remainder flat portion, mesh studies were conducted to achieve accurate results while minimizing computational time obtaining a suitable mesh size of $8 \times 8$ $\mathrm{mm}$.

Owing to the double symmetry of the geometry, boundary conditions, applied loads and observed failure modes in the experimental investigation [14], only a quarter of the section with suitable boundary conditions applied along the symmetry axes was modelled to reduce 
computational cost. The full length of the stub column was modelled for all the crosssections. Both ends of the stub column were restrained in rotation (fixed) to model the rotational restriction provided by the flat platens that apply the compression force in the test [14], in line with existing experimental and numerical investigations [9, 13, 20]. All displacements were also restrained at both ends apart from vertical displacement at the top loaded end, which was constrained using kinematic coupling to ensure uniform vertical compression represented by a vertical displacement applied to the reference point of the constraint.

An assessment of the influence of material properties on the structural response of the ferritic stainless steel stub column models was conducted by assigning various material properties to the different regions of the models. Three cases were considered: case I uses the material properties of each specimen, as given in Table 2, assigning corner material properties to the corresponding corner regions of the models and to the adjacent flat region extended up to two times the thickness of the cross-section while assigning flat material properties to the remainder regions; case II assigns the weighted average material properties of each specimen, as given in Table 3, to all the regions of the cross-section; and case III uses average material properties based on all the corner coupons and the flat coupons, as given in Table 4, assigning the former to the corner regions of all the stub column models, including the extended adjacent flat region, and the latter to the remainder regions of all the stub column models. Each particular case of study enables the identification of various situations commonly assumed in numerical modelling. While case I represents the actual material properties of the cross-section, cases II and III correspond to theoretical assumptions and are particularly appropriate to assess the accuracy of the FE model for a theoretical material (e.g. the material adopted in further parametric studies). Despite the fact that case II represents an unrealistic pattern of the cross-sectional material properties, it is simpler to incorporate into the FE and may reduce the computational time associated with models assembled with different materials. This latter approach was used in previous numerical investigations on ferritic stainless steels and showed to accurately match test data [13].

For each set of assumed material properties, the whole stress-strain response of ferritic stainless steel was simulated employing a compound version of the original Ramberg-Osgood material model [34] proposed by Mirambell and Real [35], modified by Rasmussen [36] and given in Annex D of EN 1993-1-4 [1] in terms of a multi-linear curve with parameters given in Tables 2-4. The elastic part of the multi-linear curve was described by measured Young's modulus and Poisson's ratio of 0.3 whereas the plastic part was incorporated into the FE converting the nominal (engineering) stress-strain curve into true stress $\sigma_{\text {true }}$ and logarithmic plastic strain $\varepsilon_{p l}$ curve, as given by Eqs (1) and (2), respectively.

$\sigma_{\text {true }}=\sigma_{\text {nom }}\left(1+\varepsilon_{\text {nom }}\right)$

$\varepsilon_{p l}=\ln \left(1+\varepsilon_{\text {nom }}\right)-\frac{\sigma_{\text {true }}}{E}$

Initial geometric imperfections were incorporated into the FE models as the lowest local buckling mode shape. The shape was determined through a linear eigenvalue buckling analyses and the amplitude was limited to a certain magnitude. In order to assess the influence of such limiting magnitudes on the structural response, two local imperfection amplitudes were considered: the maximum measured local imperfection $\mathrm{w}_{0}$ reported in Table 1 and the value derived from the predictive model [37, 29] of Eq. (3), where t is the plate 
thickness, $\sigma_{0.2}$ is the material $0.2 \%$ proof stress and $\sigma_{\text {cr }}$ is the elastic buckling stress of the cross-section plate elements assuming simply supported conditions. The modified Riks method was used for the geometrically and materially nonlinear analyses to determine the load-end shortening response and failure modes of all the stub column models.

$w_{0}=0.023\left(\frac{\sigma_{0.2}}{\sigma_{c r}}\right) t$

\subsection{Validation of the numerical model}

The obtained ultimate numerical loads $\mathrm{N}_{\mathrm{u} \text {.num }}$ and corresponding end shortenings $\delta_{\mathrm{u} \text {,num }}$ of the specimens are compared with the test counterparts $\mathrm{N}_{\mathrm{u} \text {,test }}$ and $\delta_{\mathrm{u} \text {,test }}$ reported in [14] to assess the sensitivity of the FE model to different some key modelling parameters and the precision to reproduce the actual structural response. The comparisons are given in Table 5 where the influence of the two imperfection amplitudes on the numerical response for the studied cases with different material properties (cases I, II and III) is presented.

Table 5. Comparison between test results and FE predictions for various materials and imperfection amplitudes

\begin{tabular}{|c|c|c|c|c|c|c|c|c|}
\hline \multirow{3}{*}{ Specimen } & \multicolumn{4}{|c|}{ Case I } & \multirow{2}{*}{\multicolumn{2}{|c|}{$\frac{\text { Case II }}{\text { Model Eq. (3) }}$}} & \multirow{2}{*}{\multicolumn{2}{|c|}{$\frac{\text { Case III }}{\text { Model Eq. (3) }}$}} \\
\hline & \multicolumn{2}{|c|}{ Measured $\mathrm{w}_{0}$} & \multicolumn{2}{|c|}{ Model Eq. (3) } & & & & \\
\hline & $\begin{array}{l}\mathrm{N}_{\mathrm{u}, \text { test }} / \\
\mathrm{N}_{\mathrm{u}, \text { num }}\end{array}$ & $\begin{array}{l}\delta_{\mathrm{u}, \text { test }} / \\
\delta_{\mathrm{u}, \text { num }}\end{array}$ & $\begin{array}{l}\mathrm{N}_{\mathrm{u}, \text { test }} / \\
\mathrm{N}_{\mathrm{u} \text {,num }}\end{array}$ & $\begin{array}{l}\delta_{\text {u,test }} / \\
\delta_{\text {u,num }}\end{array}$ & $\begin{array}{l}\mathrm{N}_{\mathrm{u}, \text { test }} / \\
\mathrm{N}_{\mathrm{u}, \text { num }}\end{array}$ & $\begin{array}{l}\delta_{\mathrm{u}, \text { test }} / \\
\delta_{\mathrm{u}, \text { num }}\end{array}$ & $\begin{array}{l}\mathrm{N}_{\mathrm{u}, \text { test }} / \\
\mathrm{N}_{\mathrm{u} \text {,num }}\end{array}$ & $\begin{array}{l}\delta_{\mathrm{u}, \text { test }} / \\
\delta_{\mathrm{u}, \text { num }}\end{array}$ \\
\hline $60 \times 60 \times 2-S C 1$ & 1.03 & 1.33 & 1.04 & 1.36 & 1.04 & 1.36 & 1.03 & 1.34 \\
\hline $60 \times 60 \times 2-S C 2$ & 1.02 & 1.32 & 1.02 & 1.35 & 1.02 & 1.35 & 1.05 & 1.33 \\
\hline $70 \times 50 \times 2-S C 1$ & 1.01 & 1.02 & 1.01 & 1.02 & 1.01 & 1.02 & 0.99 & 0.96 \\
\hline $70 \times 50 \times 2-S C 2$ & 0.97 & 1.05 & 0.96 & 1.05 & 0.96 & 1.05 & 0.99 & 1.09 \\
\hline $80 \times 40 \times 2-S C 1$ & 0.96 & 1.13 & 0.96 & 1.10 & 0.96 & 1.10 & 1.00 & 1.12 \\
\hline $80 \times 40 \times 2-S C 2$ & 0.98 & 1.14 & 1.02 & 1.40 & 1.02 & 1.40 & 1.02 & 1.13 \\
\hline $100 \times 40 \times 2-S C 1$ & 1.04 & 1.03 & 1.04 & 1.01 & 1.04 & 1.01 & 0.97 & 1.28 \\
\hline $100 \times 40 \times 2-S C 2$ & 1.00 & 1.21 & 1.00 & 1.24 & 1.00 & 1.24 & 1.01 & 1.17 \\
\hline Mean & 1.00 & 1.15 & 1.01 & 1.19 & 1.01 & 1.19 & 1.01 & 1.18 \\
\hline $\mathrm{COV}$ & 0.03 & 0.10 & 0.03 & 0.13 & 0.03 & 0.13 & 0.02 & 0.10 \\
\hline
\end{tabular}

The results show that for case I, the numerical model better matches the actual structural behaviour when the measured imperfection amplitude is used with normalised mean test to numerical ratios of 1.00 and small coefficient of variation (COV) of 0.03 . The ultimate end shortening displacement is less precise due to the slender nature of the modelled crosssections, yet acceptably predicted. This is because the cross-sections considered herein for the validation of the numerical model have a slenderness displaying the maximum imperfection sensitivity which affects the results in form of displacements. Excellent good agreement is also observed between test and numerical results for the imperfection amplitude given by Eq. (3) thereby reflecting the accuracy of its predictions. All the models generated in case I failed by local buckling at mid height as shown in Fig. 2 where it is observed that the numerical model successfully replicates structural behaviour. Hence, on the basis of this comparison, the suitability of the predictive model for the imperfection amplitude given in Eq. (3) was assessed for cases II and III. The results given in Table 5 show the reliability of the numerical model for this imperfection amplitude with normalised mean values of 1.01 and 1.01, and COV of 0.03 and 0.02 for case II and III, respectively. Given their accuracy, both approaches could be used in further parametric studies but it is believed that case III provides the models with more realistic material properties. Recall that this case differentiates the 
material properties of the flat portions and the corners of the cross-section while case II incorporates uniform cross-sectional material properties based on weighted average estimation. Thereby, an approach based on case III material properties and imperfection amplitude predicted by Eq. (3) was used in the parametric study.

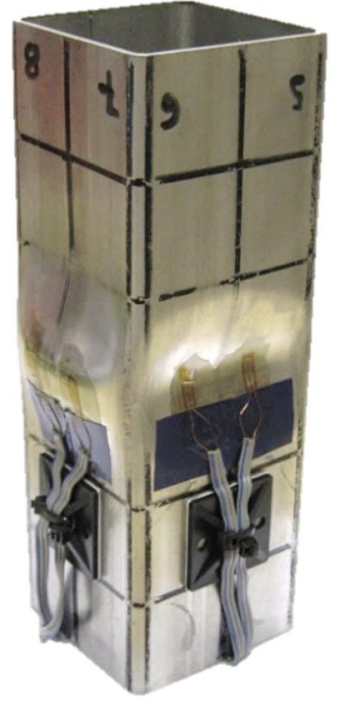

(a) Test

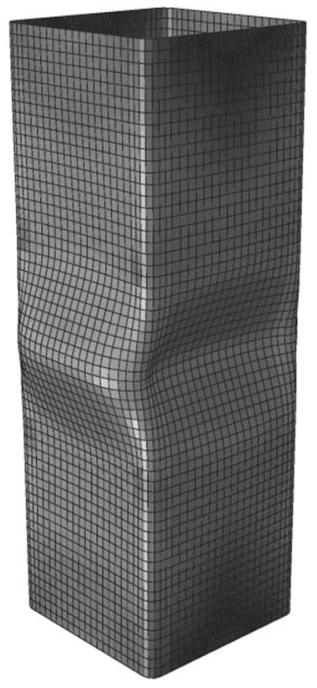

(b) FE model

Fig. 2 Comparison between test and FE failure mode for specimen $60 \times 60 \times 2-\mathrm{SC} 1$

The full load-displacement curves predicted by this approach together with the experimental curves are compared in Figs 3 and 4 for the first (SC1) and second (SC2) set of test results, respectively, on a normalised basis by the yield resistance of the gross cross-section $A \sigma_{0.2}$. Note that all specimens have failed prior to the attainment of the yield resistance due to their slender nature.

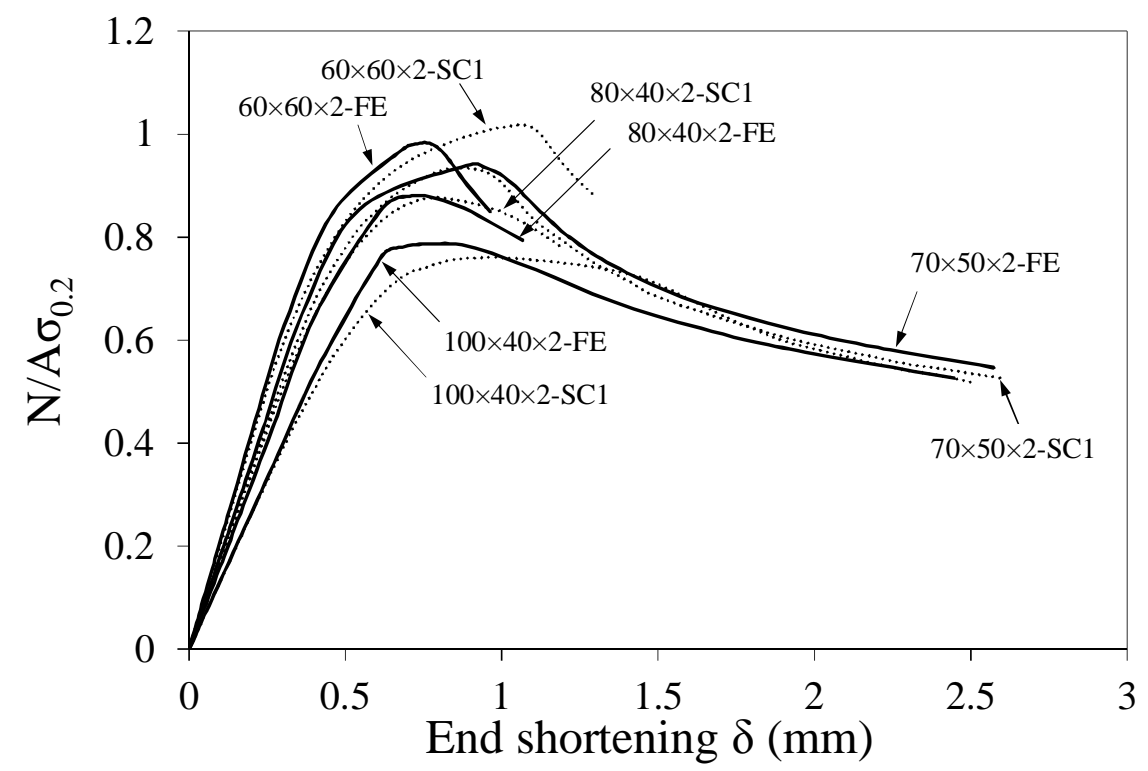

Fig. 3 Load-displacement response based on case III and initial imperfection of Eq. (3) for the first set of tests SC1 


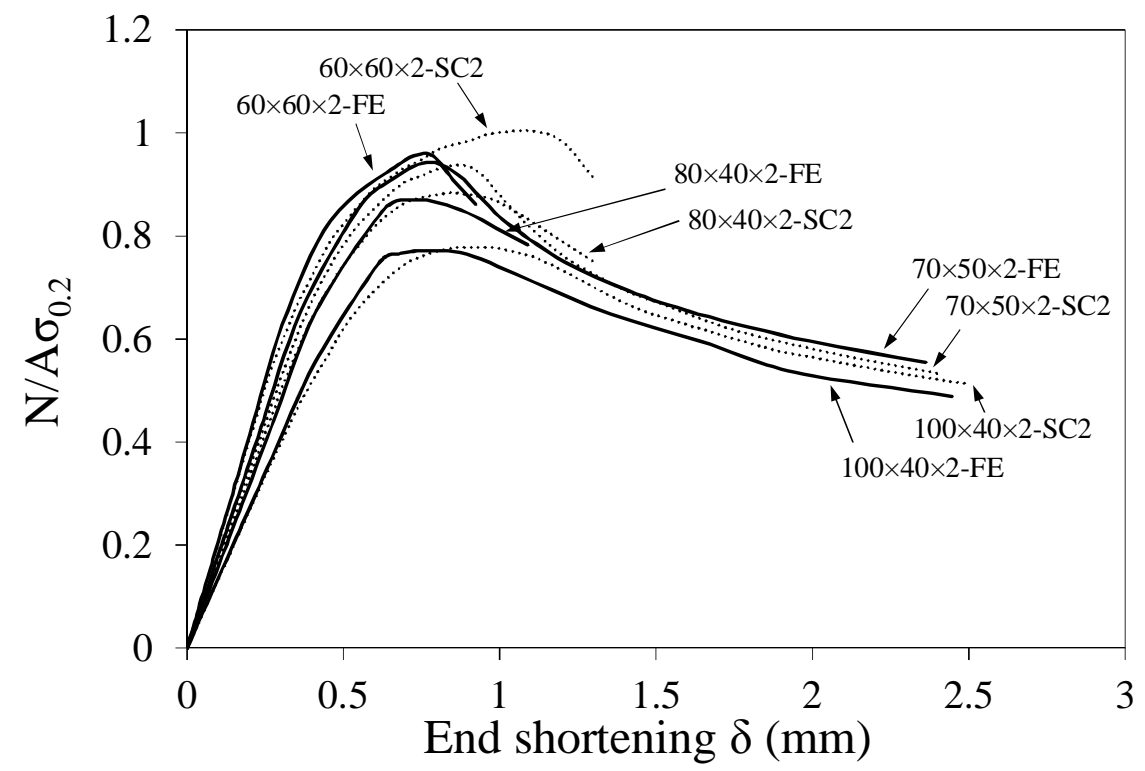

Fig. 4 Load-displacement response based on case III and initial imperfection of Eq. (3) for the second set of tests SC2

\subsection{Parametric studies}

Once the FE model was found to reasonably depict the behaviour, parametric studies were performed for the extrapolation of the test data to investigate the effects of element interaction in square and rectangular sections comprising slender elements and assess the applicability of various approaches $[1,15-20]$ for the treatment of local buckling to ferritic stainless steel.

The cross-sections under consideration were 3 SHS and 9 RHS with aspect ratios ranging from 1 to 4 . The cross-section geometry of the RHS was carefully taken so that the most slender elements, either the webs or the flanges, are Class 4 and the remainder elements are Class 3 or better. This enables to determine the actual effective area of the cross-section as only the areas of either the webs or the flanges are reduced by local buckling effects. Therefore, the cross-section geometries were $(\mathrm{h} \times \mathrm{b}): 60 \times 60,80 \times 80$ and $100 \times 100$ for the SHS; and $100 \times 80,80 \times 60,80 \times 50,100 \times 60,80 \times 40,100 \times 50,100 \times 40,120 \times 40$ and $160 \times 40$. The thickness was varied between 6 and $1 \mathrm{~mm}$ for the $160 \times 40$ cross-sections, between 4 and 1 for the $120 \times 40$ cross-sections, between 3.5 and 1 for the $100 \times 40$ and $100 \times 50$ cross-sections, and between 3 and 1 for the remaining cross-sections thereby covering a spectrum of slendernesses defined by the parameter $\mathrm{c} / \mathrm{t} \varepsilon$ from 24.6 to 236.6 , where $\mathrm{c}$ is the flat width of the cross-section plate element, $t$ is the thickness and $\varepsilon=\left[\left(235 / \sigma_{0.2}\right)(E / 210000)\right]^{0.5}$. The length of all the models was set equal to three times the largest cross-section dimension as recommended in EN 1993-1-3 [38]. The material properties adopted are given in Table 4, which were appropriately assigned to the different regions of the models as discussed above, and the local imperfection amplitude was predicted through Eq. (3). A total number of 124 models were generated.

\section{Methods for cross-section design and discussion of results}

\subsection{General}

In the following sub-sections, the obtained numerical results are used to assess the applicability of available design approaches for cross-section design that were developed for carbon steel and/or other stainless steel to ferritic stainless steel. Various methods have been considered: methods based on effective width theory and cross-section classification concept 
which neglect interaction effects and include the approach given in EN 1993-1-4 [1] and revised by Gardner and Theofanous [15]; the regression analysis method proposed by Kato [18] and modified by Theofanous and Gardner [19] which explicitly compute the local buckling resistance and allow for element interaction; and methods based on gross crosssection that also allow element interaction including the Direct Strength Method (DSM) developed by Schafer [16] and adapted for stainless steel by Becque et al. [17] and the effective cross-section method proposed by Zhou et al. [20]. These design approaches are first outlined and their performance and application to ferritic stainless steel is assessed thereafter. A comparison of the predicted cross-section resistances by those methods is given and discussed. For the various appraisals, all partial safety factors were set to unity to allow a direct comparison between predicted $\mathrm{N}_{\mathrm{u} \text {,pred }}$ and numerical loads achieved in the models $\mathrm{N}_{\mathrm{u}, \mathrm{num}}$.

\subsection{Available design provisions for local buckling \\ 3.2.1 The effective with method}

The treatment of local buckling within the European design rules for application to stainless steel, EN 1993-1-4 [1], is underpinned by the concept of cross-section classification and the effective width method. The slenderness of each compression part in a cross-section expressed by the parameter $\mathrm{c} / \mathrm{t} \varepsilon$, where $\mathrm{c}$ is the flat width of the cross-section plate element, $\mathrm{t}$ is the thickness and $\varepsilon=\left[\left(235 / \sigma_{0.2}\right)(E / 210000)\right]^{0.5}$, is compared with limiting slenderness values and placed into four discrete behavioural classes (Class 1 to 4 ) and the whole cross-section adopts the behaviour of the most unfavorable (slender) plate element. These slenderness limits depend on the nature of the cross-section, the type of the plate elements (internal elements or outstand flanges) and their stress gradient. The Class 3 limiting value marks the boundary between fully effective or stocky cross-sections (Class 1 to 3 ) and those that lose effectiveness due to local buckling effects (Class 4). The cross-sectional design of Class 4 or slender cross-sections is dealt with the effective width method which applies a reduction factor $\rho$ to determine the effective widths of the individual plate elements. Eqs (4) and (5) provide the current expression of this reduction factor $\rho$ for internal elements given in EN 1993-1-4 [1] and the one revised by Gardner and Theofanous [15], respectively, where $\bar{\lambda}_{p}=\sqrt{\sigma_{0.2} / \sigma_{c r}}$ is the non-dimensional plate slenderness. This parameter requires the elastic buckling stress $\sigma_{\mathrm{cr}}$ of the most slender constituent plate element for its computation which can be determined by using the classical analytical expressions for individual plates $\sigma_{c r}=$ $k_{\sigma} \pi^{2} E(t / h)^{2} / 12\left(1-v^{2}\right)$ as given by EN 1993-1-5 [39]. The stress distribution of the plate element is considered through the buckling factor $\mathrm{k}_{\sigma}$ which assumes simply supported conditions at the plate edges thereby neglecting the above mentioned element interaction effects in RHS. $\mathrm{k}_{\sigma}$ is taken as 4.0 for internal elements in compression.

The application limit of the effective width method is established setting the reduction factor $\rho$ to unity and deducting the non-dimensional slenderness $\bar{\lambda}_{p}$. The resulting boundaries are given in Eqs (4) and (5) for the approaches under consideration which can also be expressed in terms of the slenderness parameter through $\mathrm{c} / \mathrm{t} \varepsilon=56.8 \bar{\lambda}_{p}$ to define the Class 3 slenderness limiting value. Hence, for internal elements in compression, EN 1993-1-4 [1] establishes a Class 3 slenderness limit of 30.7 while the revised equation by Gardner and Theofanous [15] sets a less restrictive value of 37. It should be mentioned that this revised equation for $\rho$ proposed in [15] as given by Eq. (5) has been considered in the present study as it showed to improve cross-section resistance predictions [14]. 
$\rho=\frac{0.772}{\bar{\lambda}_{p}}-\frac{0.125}{\bar{\lambda}_{p}^{2}} \leq 1$ internal elements with $\bar{\lambda}_{p} \geq 0.541[1]$

$\rho=\frac{0.772}{\bar{\lambda}_{p}}-\frac{0.079}{\bar{\lambda}_{p}^{2}} \leq 1$ for internal elements with $\bar{\lambda}_{p} \geq 0.651[15]$

The cross-sectional properties are determined for the effective cross-section and a simple bilinear elastic-perfectly plastic stress strain material model is assumed with attainable maximum stresses of $\sigma_{0.2}$. This simplification, which is a merely adoption of the structural carbon steel material response deviates of the actual stress-strain behaviour of stainless steel which display considerable strain hardening and might lead to over-conservative predictions especially for stocky cross-sections where failure occurs at stress levels beyond $\sigma_{0.2}$. Unlike slender sections, where local buckling occurs prior to yielding, the effects of element interaction are of little significance in stocky cross-sections since material strain hardening strongly influences and controls their structural response. Exploitation of the material strain hardening properties has been examined elsewhere [40,13].

Although EN 1993-1-4 [1] currently includes three ferritic grades (1.4003, 1.4016 and 1.4512), the applicability of the cross-section design provisions for the treatment of local buckling is yet to be validated. This has been performed in existing investigations [13, 14] and extended herein for cross-sections with different aspect ratios.

\subsubsection{The regression analysis design method}

The regression analysis design method was firstly proposed by Kato [18, 41] while examining the flange-web interaction and the material strain hardening influence on the rotation capacity response. Through regression analysis of available test data on stub columns, it was proposed a semi-empiric design method to determine the normalised local buckling strength in terms of the $\sigma_{0.2} / \sigma_{\mathrm{LB}}$ ratio, upon which to base rotation capacity predictions. The general form of this equation is given by Eq. (6), where $\sigma_{L B}=N_{u} A$ is the maximum compressive stress and $\alpha_{\mathrm{f}}$ and $\alpha_{\mathrm{w}}$ are slenderness parameters of the flange and the web respectively, and A, B and C are coefficients to fit in with data. This approach allows for both element interaction effects and material strain hardening, and its versatility led to the adaptation of the method to cover various materials and types of loading including carbon and high strength steel I-section beams in flexure [42, 43] as well as stainless steel crosssections in compression. This latter adaptation was performed by Theofanous and Gardner [19], where regression analyses of numerical data on austenitic and duplex stainless steels compressed RHS resulted in the expression given in Eq. (7) where $\bar{\lambda}_{p, f}$ and $\bar{\lambda}_{p, w}$ are the flange and the web non-dimensional slenderness, respectively. The suitability of this method for application to ferritic stainless steel needs to be verified.

$$
\begin{aligned}
& \frac{\sigma_{0.2}}{\sigma_{L B}}=A+\frac{B}{\alpha_{f}}+\frac{C}{\alpha_{w}} \\
& \frac{\sigma_{0.2}}{\sigma_{L B}}=0.53+0.1 \bar{\lambda}_{p, f}+0.6 \bar{\lambda}_{p, w}
\end{aligned}
$$

\subsubsection{The direct strength method (DSM)}

Slender cross-sections are well-established construction products that offer optimum dimensions to suit structural requirements. Due to the resulting optimised cross-section geometry, which often involves the usage of edge and/or intermediate stiffeners, leads the 
designers to deal with complex failure modes and interaction effects thereof. The direct strength method (DSM) has been pioneered by Schafer [16] and is based upon the idea that the reduction factor due to an instability related failure mode $\rho$ and hence the strength of a member can be determined on the basis of the relevant elastic critical buckling stresses for the instability modes considered and the yield stress. A specific piece of software based on the constrained Finite Strip Method named CUFSM [44] and analytical methods for the full cross-section [45] have been developed to determine the elastic buckling stresses. Their usage within the DSM is not mandatory but highly recommended to account for the non-linear behaviour of cold-formed steel members and exploit the potential of the DSM. The DSM was adopted in the North American AISI S100-12 [46] design rules and the Australian AS/NZS 4600 [47] specifications for cold-formed steel as an alternative design approach for crosssection and beam design of structural steel when the effective width method turns into tedious calculations owing to the complexity of the geometry of the cross-section.

Investigation towards the adaptation of the DSM for stainless steel was performed by Becque et al. [17], where direct strength curves for flexural, torsional and flexural-torsional buckling were derived based on a database of experimental and numerical studies on stainless steel SHS, RHS, I-section and lipped channel sections. The DSM curve considered in the present paper for local buckling design is the proposed curve by Becque et al. [17] for flexural buckling given in Eq. (8) where $\bar{\lambda}_{c s}=\sqrt{\sigma_{0.2} / \sigma_{c r, c s}}$ is the non-dimensional slenderness of the cross-section computed by using the open source software CUFSM to determine the elastic critical stress of the cross-section $\sigma_{c r, c s}$. The cross-section resistance is therefore determined multiplying this reduction factor by the yield resistance $A \sigma_{0.2}$. Note that the DSM also limits the $0.2 \%$ proof stress as the maximum attainable stress thereby neglecting the strain hardening effects. Moreover, the method turns into conservative predictions for very slender cross-sections since the cross-section is treated as a single element assuming that if a small slender element locally buckles, the whole cross-section undergoes local buckling. Its performance for design of ferritic stainless steel slender SHS and RHS is assessed in the present study.

$\rho=\frac{0.95}{\bar{\lambda}_{c s}}-\frac{0.22}{\bar{\lambda}_{c s}^{2}} \quad$ for $\bar{\lambda}_{c s}>0.55$

\subsubsection{The effective cross-section method}

The underlying concept of the effective cross-section method proposed by Zhou et al. [20] steams from the same principles of the effective width method in terms of cross-section classification deducting the ineffective areas of the cross-section due to local buckling effects. What differentiates the method is that the reduction factor $\rho$ given in Eq. (9) is applied to the gross cross-sectional area instead of to the individual plate elements. Moreover, this design method incorporates a function $\phi(\alpha)$ of the aspect ratio $\alpha$, thus considering element interaction effects explicitly as given by Eq. (10). The non-dimensional slenderness is determined in the same way as within the effective width method. In order to ensure continuity with this reduction factor $\rho$, Zhou et al. [20] also derived a Class 3 slenderness limit function of the aspect ratio $\alpha$ as given by Eq. (11). The coefficients of Eqs (9-11) were determined through regression analyses of numerical data on high strength stainless steel compressed SHS and RHS and the method applies when $1 \leq \alpha \leq 6,448 \leq \sigma_{0.2} \leq 707 \mathrm{MPa}$ and $27.3 \leq \mathrm{c} / \mathrm{t} \varepsilon \leq 91$ (or $0.48 \leq \bar{\lambda}_{p} \leq 1.6$ ). The suitability of this method for application to ferritic stainless steel was first experimentally examined in [14] where it was stated the necessity to undertake further research on this topic and this is conducted herein. 
$\rho= \begin{cases}\frac{0.772}{\bar{\lambda}_{p}} \phi(\alpha)-\frac{0.059}{\bar{\lambda}_{p}^{2}} \phi(\alpha)^{2}+0.01 \alpha \bar{\lambda}_{p}^{2} \leq 1 & \text { for } \bar{\lambda}_{p}>0.686 \text { and } 1 \leq \alpha \leq 3 \\ \frac{0.907}{\bar{\lambda}_{p}}-\frac{0.081}{\bar{\lambda}_{p}^{2}}+0.03 \bar{\lambda}_{p}^{2} \leq 1 & \text { for } \bar{\lambda}_{p}>0.686 \text { and } \alpha>3\end{cases}$

$\phi(\alpha)=\frac{30.5+10.2 \alpha-1.7 \alpha^{2}}{39}$ for $1 \leq \alpha \leq 3$

$\frac{c}{t \varepsilon}= \begin{cases}30.5+10.2 \alpha-1.7 \alpha^{2} & \text { for } 1 \leq \alpha \leq 3 \\ 45.8 & \text { for } \alpha>3\end{cases}$

\subsection{Assessment of the design methods}

\subsubsection{Methods based on plate width}

For this assessment, the reduction factor of the most slender constituent element of the crosssection defined as $\rho=\left(N_{u, \text { num }} / \sigma_{0.2}-A_{r}-2 \cdot t \cdot c_{f}\right) / 2 \cdot t \cdot c_{w}$, where $\mathrm{N}_{\mathrm{u} \text {,num }}$ is the ultimate load achieved in the numerical models, $\sigma_{0.2}$ is the $0.2 \%$ proof stress, $\mathrm{A}_{\mathrm{r}}$ is the area of the corners, $t$ is the thickness and $c_{f}$ and $c_{w}$ are the flat portion of the flange and the web, respectively, is plotted against the non-dimensional slenderness $\bar{\lambda}_{p}$ of the element controlling local buckling behaviour in Fig. 5 where the trends of the numerical results for varying aspect ratios $\alpha=\mathrm{h} / \mathrm{b}$ are shown. The corresponding effective width equation given in EN 1993-1-4 [1] and proposed in [15] are also depicted. In Fig. 5 it is observed that the trends of the numerical results for $\alpha>1$ (RHS) display higher values for the reduction factor to their SHS $(\alpha=1)$ counterparts of equal non-dimensional slenderness $\bar{\lambda}_{p}$ reflecting the higher level of restraint of the slender plate elements provided by the narrow parts of the cross-section. The trends corresponding to the various RHS curves converge towards the SHS curve at higher slenderness values for higher aspect ratios reflecting the plate slenderness up to which the effects of element interaction are beneficial for the various aspect ratios. Fig. 5 also shows that the effective width equation for internal compressed elements given in EN 1993-1-4 [1] is safe for application to ferritic stainless steel, though the expression proposed by Gardner and Theofanous [15] falls closer to the numerical data thereby leading to improved crosssection resistance predictions.

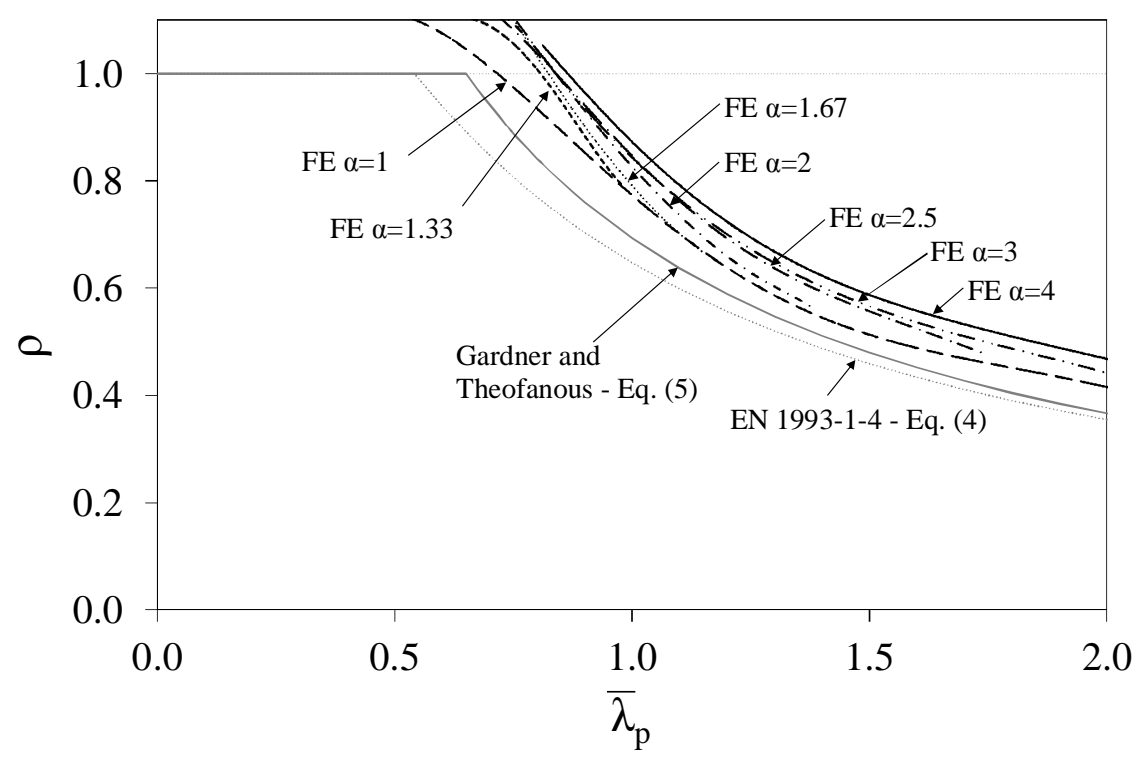

Fig. 5 Assessment of methods based on effective plate width [1, 15] 


\subsubsection{Regression analysis method}

The appraisal of the equation proposed in [19] and given by Eq. (7) is shown in Fig. 6 in terms of normalised ultimate load by the yield resistance $A \sigma_{0.2}$. The results show that the proposed equation to allow for element interaction effects for austenitic and duplex stainless steels [19] is applicable to ferritic stainless steel providing fairly appropriate predictions. A maximum unsafe discrepancy of 3\%, yet acceptable, is observed for SHS between the predicted values and the limiting partial safety factor line of $\gamma_{\mathrm{M} 0}=1.1$, which is the value recommended in EN 1993-1-4 [1], for the points falling below this line as shown in Fig. 6.

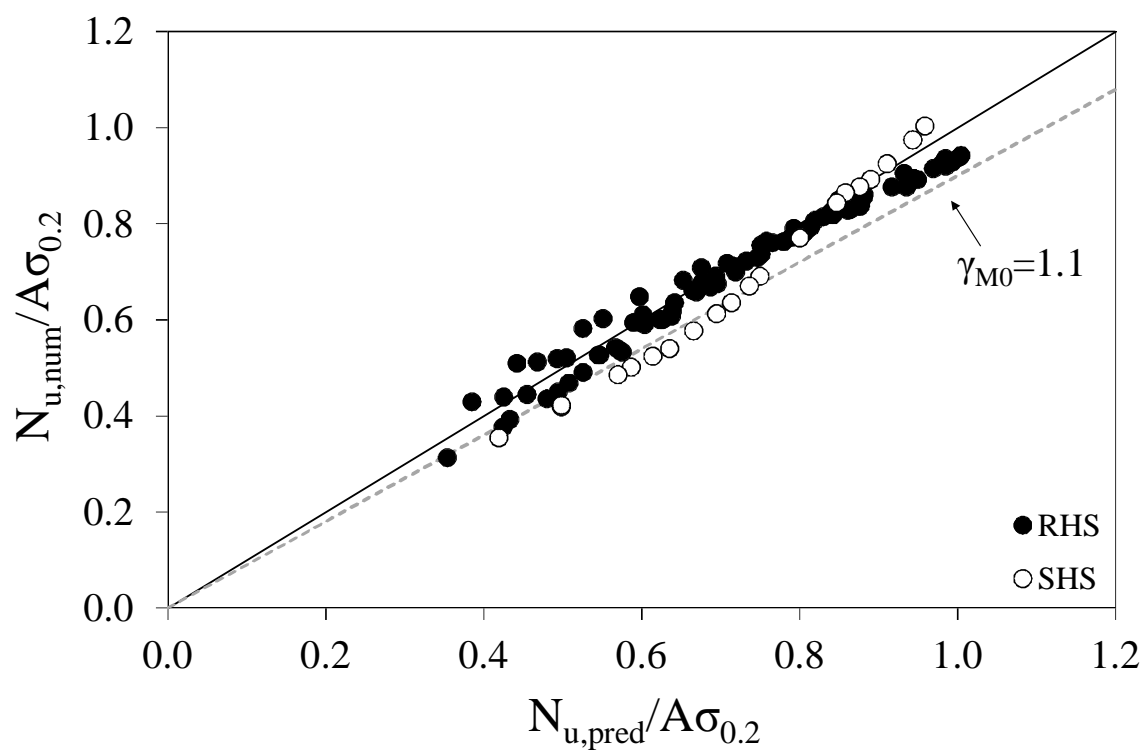

Fig. 6 Comparison between numerical and predicted resistances for the regression analysis method [19]

\subsubsection{Methods based on gross cross-section}

The methods assessed herein are the DSM for stainless steel [17] and the effective crosssection method proposed by Zhou et al. [20]. The ultimate numerical load normalised by the squash load has been plotted against the non-dimensional cross-section slenderness $\bar{\lambda}_{c s}$ determined by using the CUFSM for the former approach and the slenderness of the most slender plate $\bar{\lambda}_{p}$ for the latter method in Figs 7 and 8, respectively. The results depicted in Fig. 7 show that the DSM [17] curve falls below the numerical results thereby providing safe predictions for ferritic stainless steel, though the method is slightly conservative for the RHS as their trend line follows a different path for $\bar{\lambda}_{c s}$ values higher than 1.18 of that displayed by the SHS which closely follows the DSM curve. Fig. 8 shows that the curves proposed by Zhou et al. [20] better match the numerical results for $\bar{\lambda}_{p} \leq 2.11$ but might provide optimistic results when $\bar{\lambda}_{p}>2.11$. This is associated with the application limit of the method in terms of $\bar{\lambda}_{p}$ which was set out as $0.48 \leq \bar{\lambda}_{p} \leq 1.6$. Note that despite this, the method provides safe predictions for the numerical data falling between $1.6 \leq \bar{\lambda}_{p} \leq 2.11$. In assessing the suitability of the Class 3 slenderness limits as a function of the aspect ratio proposed by Zhou et al. [20] for application to ferritic stainless steel, the normalised ultimate numerical load has been plotted against the slenderness parameter $\mathrm{c} / \mathrm{t} \varepsilon$ of the most slender constituent plate element in Fig. 9, together with the Class 3 limit given in EN 1993-1-4 [1] and revised value proposed by 
Gardner and Theofanous [15] for comparison purposes. From Fig. 9, it is observed good agreement between the numerical data and the various slenderness limiting values related to their corresponding aspect ratios. Hence, it can be concluded that Zhou et al. [20] approach is suitable for the design of ferritic stainless steel cross-sections when $\bar{\lambda}_{p} \leq 2.11$ but provides optimistic predictions when $\bar{\lambda}_{p}>2.11$.

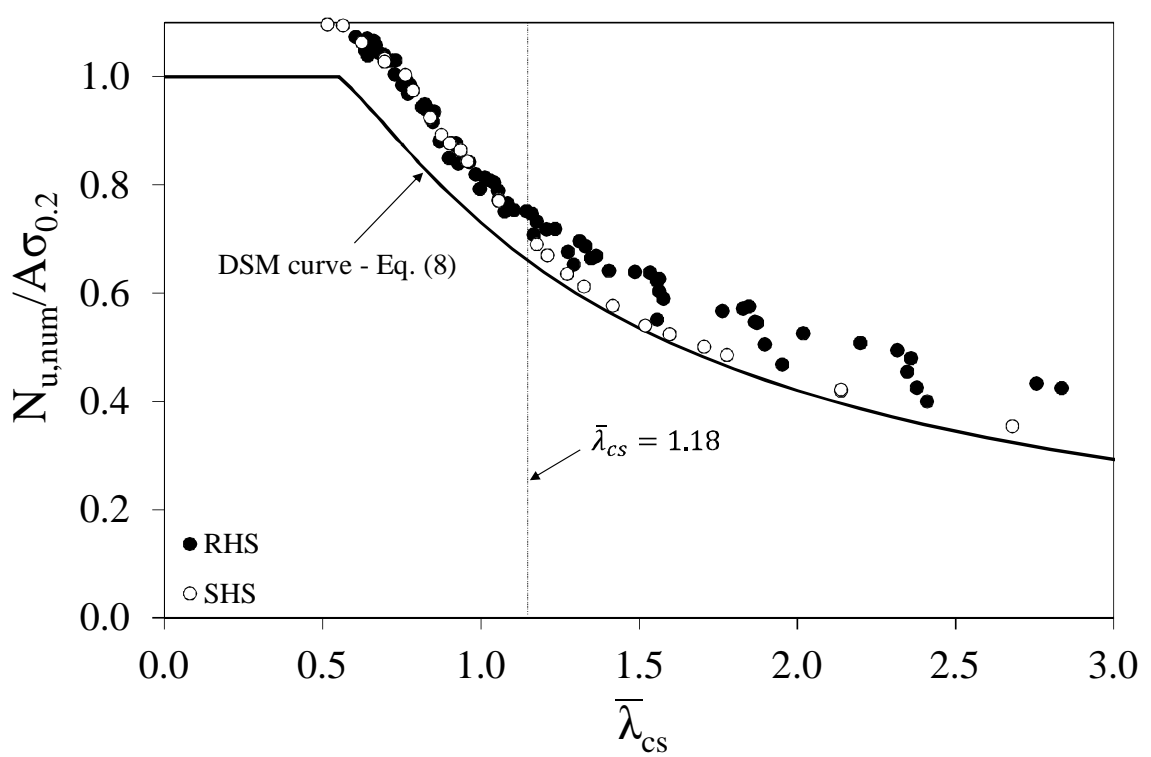

Fig. 7 Performance of the DSM [17] when applied to ferritic stainless steel

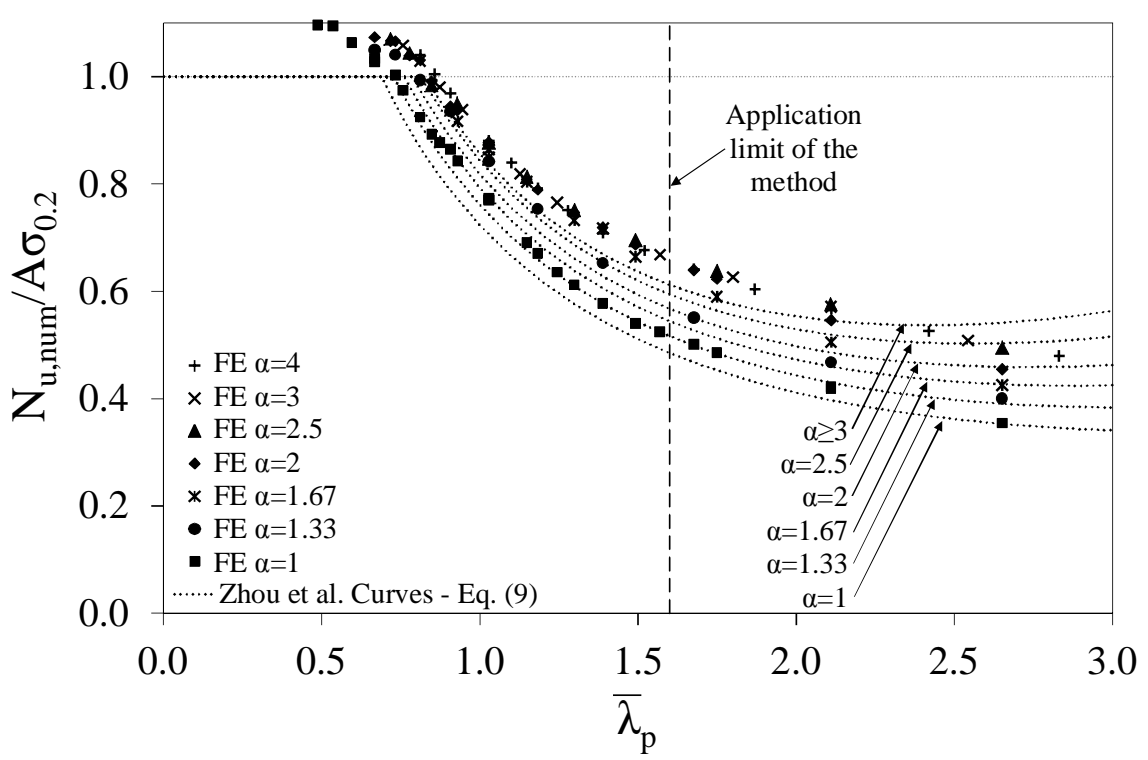

Fig. 8 Assessment of the method proposed by Zhou et al. [20] 


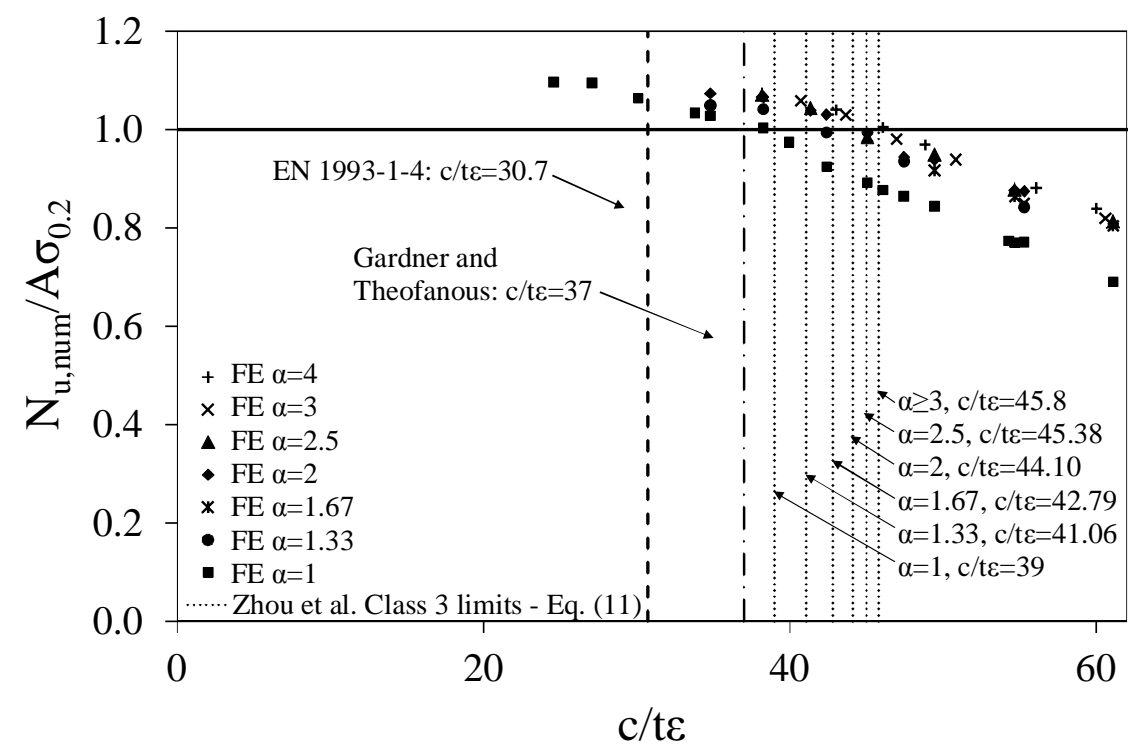

Fig. 9 Assessment of the Class 3 slenderness limits proposed by Zhou et al. [20]

\subsubsection{Discussion}

Overall, all the methods assessed along the previous sub-sections showed safe predictions for application to ferritic stainless steel. This is summarized in Table 6 where the mean predictions and coefficient of variation $(\mathrm{COV})$ of the various design approaches relative to the numerical results are given. This table provides the results for various sets of data where only those cross-sections failing prior to the attainment of the yield resistance $\left(\mathrm{N}_{\mathrm{u} \text {,num }}<A \sigma_{0.2}\right)$ were considered to enable a more representative comparison among the various methods. The results show that the most accurate mean predictions are provided by the regression analysis method adapted for stainless steel by Theofanous and Gardner [19] with mean values of 1.004, though the method is too optimistic for SHS. For the DSM, it is observed that the method performs better for SHS than for RHS on a mean basis, although conversely the method should perform similarly for both types of cross-sections. Recall that the RHS modelled herein comprise very slender elements which particularly affect DSM predictions and do not allow the potential of this design approach to be highlighted. Table 6 also shows the significant improvement proposed by Gardner and Theofanous [15] for the effective width equation given in EN 1993-1-4 [1], though it is not as accurate as the proposed method by Zhou et al. [20]. Hence, building on the proposed curve by Gardner and Theofanous [15] which is in line with the essence of the effective width theory currently employed in EN 1993-1-4 [1] for cross-section design, a revised expression explicitly accounting for element interaction is proposed in the present study to bring this design approach to the same level of these alternative design methods considering such interaction effects.

Table 6. Assessment of various design methods for application to ferritic stainless steel

\begin{tabular}{|c|c|c|c|c|c|c|}
\hline & & $\begin{array}{c}\text { EN 1993-1-4 } \\
{[1]}\end{array}$ & $\begin{array}{c}\text { Gardner and } \\
\text { Theofanous [15] }\end{array}$ & $\begin{array}{l}\text { Theofanous and } \\
\text { Gardner [19] }\end{array}$ & $\begin{array}{c}\text { DSM } \\
{[17]}\end{array}$ & Zhou et al. [20] \\
\hline & & $\mathrm{N}_{\mathrm{u}, \text { num }} /$ & $\mathrm{N}_{\mathrm{u}, \mathrm{num}} /$ & $\mathrm{N}_{\mathrm{u}, \text { num }} /$ & $\mathrm{N}_{\mathrm{u}, \text { num }} /$ & $\mathrm{N}_{\mathrm{u}, \mathrm{num}} /$ \\
\hline & & $\mathrm{N}_{\mathrm{u}, \text { pred }}$ & $\mathrm{N}_{\mathrm{u} \text {,pred }}$ & $\mathrm{N}_{\mathrm{u}, \text { pred }}$ & $\mathrm{N}_{\mathrm{u}, \text { pred }}$ & $\mathrm{N}_{\mathrm{u}, \text { pred }}$ \\
\hline \multirow{2}{*}{ SHS } & Mean & 1.153 & 1.093 & 0.927 & 1.081 & 1.069 \\
\hline & $\mathrm{COV}$ & 0.028 & 0.020 & 0.076 & 0.038 & 0.019 \\
\hline \multirow{2}{*}{ RHS } & Mean & 1.159 & 1.108 & 1.024 & 1.153 & 1.056 \\
\hline & $\mathrm{COV}$ & 0.033 & 0.036 & 0.048 & 0.064 & 0.093 \\
\hline \multirow{2}{*}{$\begin{array}{l}\text { SHS and } \\
\text { RHS }\end{array}$} & Mean & 1.158 & 1.105 & 1.004 & 1.138 & 1.059 \\
\hline & $\mathrm{COV}$ & 0.032 & 0.034 & 0.067 & 0.065 & 0.083 \\
\hline
\end{tabular}




\section{Proposed design approach allowing for the benefits of element interaction}

A new design approach is developed herein based on the cross-section classification concept and the effective width theory so as to explicitly account for the benefits of interaction effects. The method adopts the Class 3 slenderness limit of 37 and effective width equation given in Eq. (5) proposed by Gardner and Theofanous [15] and seeks appropriate functions of the aspect ratio $\alpha$ to incorporate into them.

\subsection{Development of the Class 3 limit as a function of the aspect ratio}

To start with, the numerical results from the parametric study were used to generate analytical equations following the generalised Winter based function $\rho=\mathrm{A} / \bar{\lambda}_{p}^{B}$. These equations are shown in Fig. 10 for the various aspect ratios $\alpha$ and were fit through a process of least squares regression exhibiting $\mathrm{R}^{2}$ coefficient values around 0.99 . The non-dimensional slenderness $\bar{\lambda}_{p}$ values providing reduction factors of $\rho=1$ were deducted thereafter and expressed in terms of the slenderness parameter $\mathrm{c} / \mathrm{t} \varepsilon$, as given in Table 7 . Recall that the relationship between $\bar{\lambda}_{p}$ and $\mathrm{c} / \mathrm{t} \varepsilon$ is determined by the expression $\mathrm{c} / \mathrm{t} \varepsilon=56.8 \bar{\lambda}_{p}$. The slenderness parameter $\mathrm{c} / \mathrm{t} \varepsilon$ has been plotted against the aspect ratio $\alpha$ in Fig. 11 where the continuous line, which was generated through a process of least squares regression, depicts the proposed Class 3 limit expression incorporating the aspect ratio $\alpha$ as given by Eq. (12). In Fig. 11, note that this proposed equation resembles that proposed by Zhou et al. [20] for high strength steel which has been validated in the present study for application to ferritic stainless steel.

$\frac{c}{t \varepsilon}= \begin{cases}28.3+10.4 \alpha-1.8 \alpha^{2} & \text { for } 1 \leq \alpha \leq 3 \\ 43.3 & \text { for } \alpha>3\end{cases}$

Table 7. $\bar{\lambda}_{p}$ and $\mathrm{c} / \mathrm{t} \varepsilon$ values providing $\rho=1$ for the various aspect ratios $\alpha$

\begin{tabular}{cccccccc}
\hline$\alpha$ & 1 & 1.33 & 1.67 & 2 & 2.5 & 3 & 4 \\
\hline $\bar{\lambda}_{p}$ & 0.651 & 0.721 & 0.741 & 0.758 & 0.763 & 0.767 & 0.768 \\
$\mathrm{c} / \mathrm{t} \varepsilon$ & 37 & 40.94 & 42.09 & 43.05 & 43.33 & 43.55 & 43.63 \\
\hline
\end{tabular}

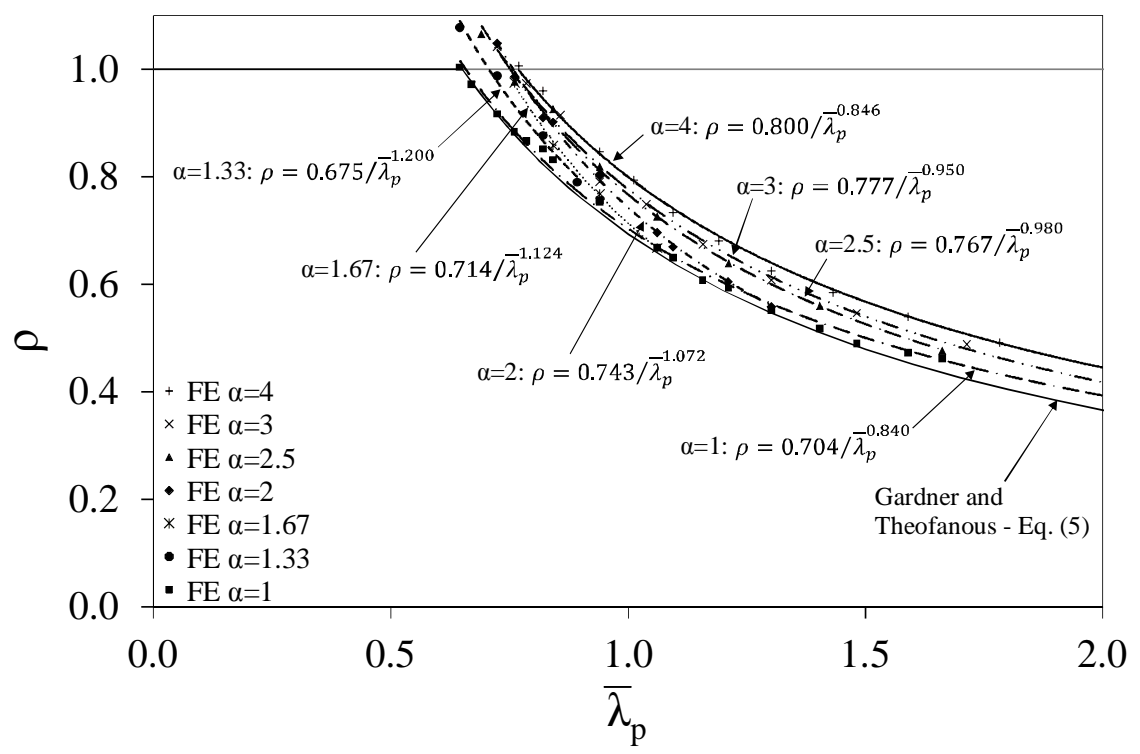

Fig. 10 Generated analytical equations for the various aspect ratios $\alpha$ 


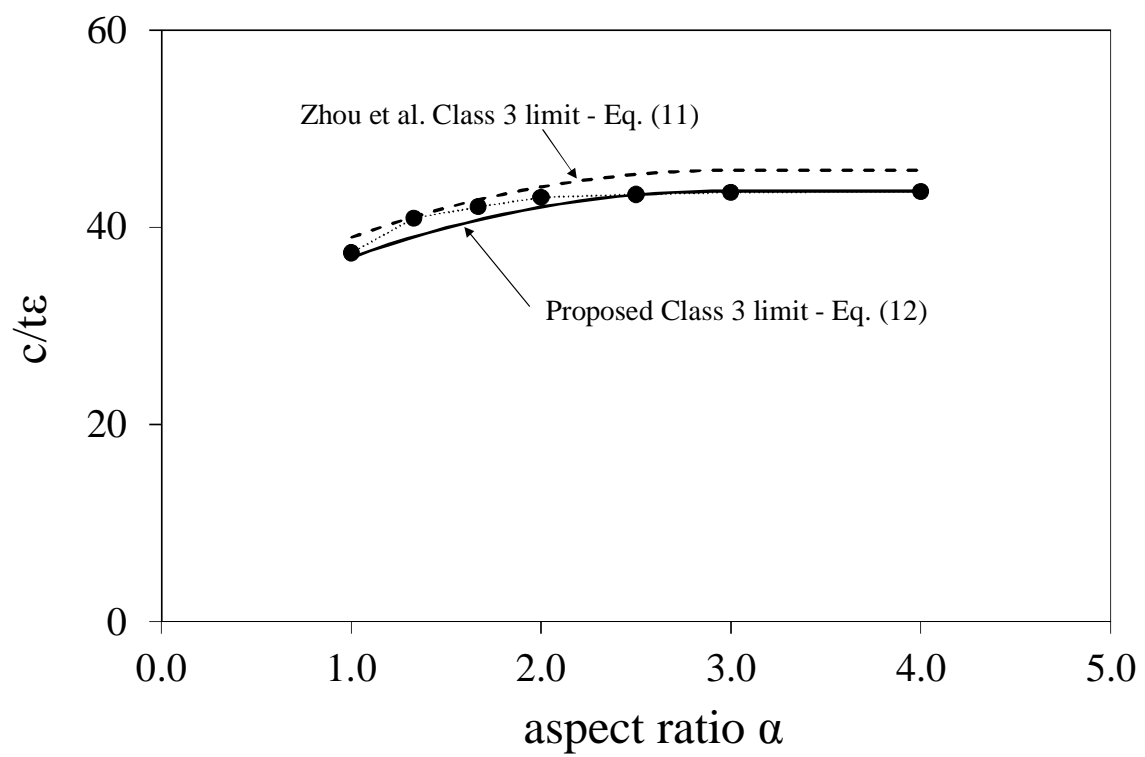

Fig. 11 Relationship between the Class 3 limit and the aspect ratio $\alpha$

\subsection{Incorporation of the aspect ratio $\alpha$ within the reduction factor $\rho$}

The values of the coefficients A and B for the various curves generated in Fig. 10 are plotted against the corresponding aspect ratio of the curve in Fig. 12 so as to derive appropriate equations as a function of the aspect ratio $\alpha$ for the parameters $\mathrm{A}$ and $\mathrm{B}$ of the generalised Winter based function $\rho=\mathrm{A} / \bar{\lambda}_{p}^{B}$. The equations for such coefficients are depicted in Fig. 11 and incorporated within the effective width equation proposed by Gardner and Theofanous [15]. This results in the proposed equation for cross-section design allowing for the benefits of element interaction given in Eq. (13).

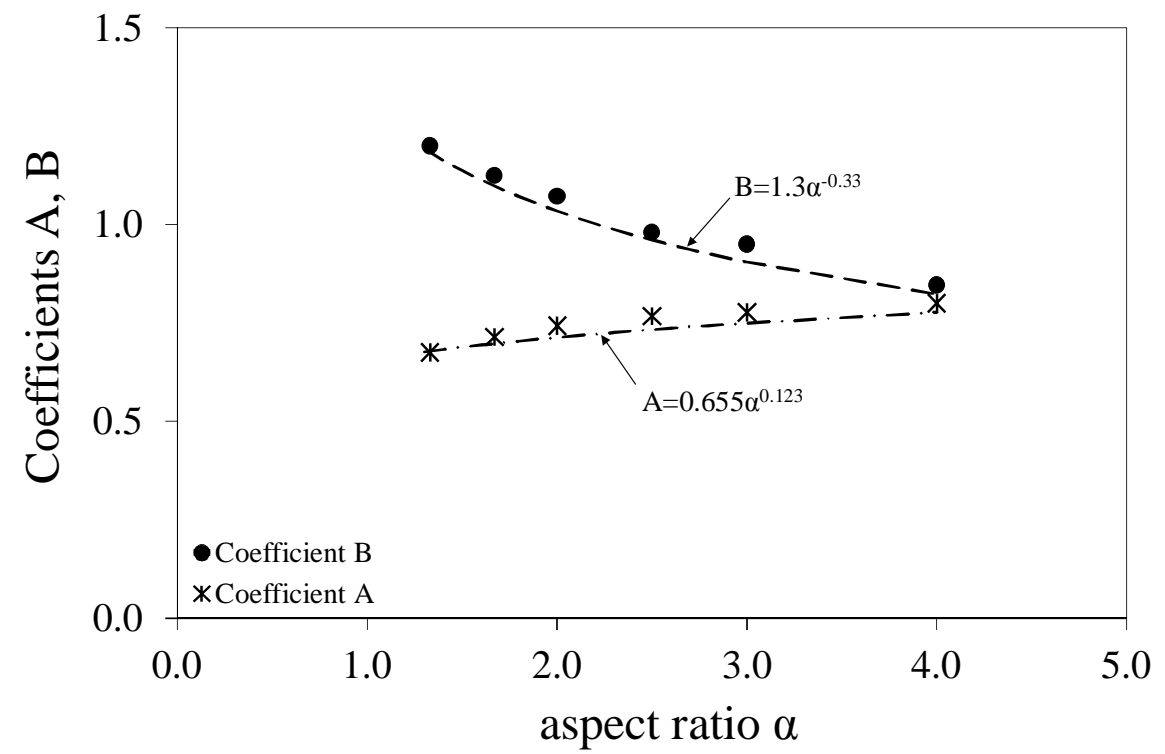

Fig. 12 Coefficients A and B as a function of the aspect ratio $\alpha$

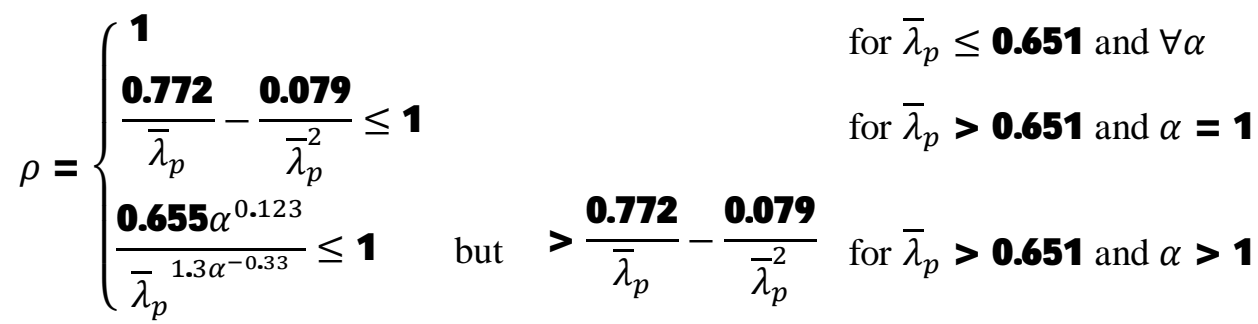




\subsection{Reliability analysis}

The proposed effective width equation accounting for the benefits of element interaction given in Eq. (13) is statistically validated in this section following guidelines of Annex D of EN 1990 [26]. The results are shown in Table 8 where $k_{d, n}$ is the design fractile factor (ultimate state) for the number of tests $n$ taken into consideration, $b$ is the slope of the least squares regression that reflects the relationship between the numerical and predicted resistances, $\mathrm{V}_{\delta}$ is the coefficient of variation of the numerical values relative to the resistance model, $V_{\mathrm{FEM}}$ is the coefficient of variation of the FE model $[48,49]$ and $\mathrm{V}_{\mathrm{r}}$ is the combined coefficient of variation including all the uncertainties. The results show that for a material overstrength of 1.2 with a $\mathrm{V}_{\mathrm{xi}}=0.045$ for the material strength and a value of $\mathrm{V}_{\mathrm{xi}}=0.05$ for the geometry [50], the proposed effective width equations allowing for element interaction provide a partial safety factor $\gamma_{\mathrm{M} 0}$ of 0.96 . The partial safety factor $\gamma_{\mathrm{M} 0}$ given in EN 1993-1-4 [1] for stainless steel is 1.1 , hence the proposed design equation is reliable for this value.

Table 8. Results of the reliability analysis

\begin{tabular}{ccccccc}
\hline $\mathrm{n}$ & $\mathrm{k}_{\mathrm{d}, \mathrm{n}}$ & $\mathrm{b}$ & $\mathrm{V}_{\delta}$ & $\mathrm{V}_{\text {FEM }}$ & $\mathrm{V}_{\mathrm{r}}$ & $\gamma_{\mathrm{M} 0}$ \\
\hline 82 & 3.213 & 1.077 & 0.025 & 0.026 & 0.079 & 0.96 \\
\hline
\end{tabular}

\subsection{Applicability of the method to the generated models and other stainless steel}

The predictions of the proposed design method are given together with those of the EN 19931-4 in Fig. 13 for the generated FE models and existing test results collected from the literature $[5-8,10,14]$ on various stainless steel. Only Class 4 cross-sections with aspect ratios $\alpha$ over 1 were considered for both sets of data to enable a better assessment of the proposed design approach. This necessary consideration resulted in a significant reduction of the available number of data in the test set, though the amount of data is still representative enough to validate the proposed approach on an experimental results basis. In Fig. 13 it is observed a reduction in scatter and translation of the points downwards reflecting a decreasing mean with all the values for both sets of data falling on the safe side. Table 9 shows the predicted resistances on the basis of mean and COV relative to the numerical or test results. In Table 9, the predictions of the proposed equation by Gardner and Theofanous [15] were also considered. The results show that the proposed effective width equation accounting for element interaction achieves better predictions than current EN 1993-1-4 [1] and proposed effective width equation in [15] reducing mean and scatter, hence leading to a more efficient design and allowing to confirm its applicability to any stainless steel grade.

Table 9. Comparison between numerical results, collected tests and various design approaches

\begin{tabular}{|c|c|c|c|c|c|c|}
\hline & \multicolumn{3}{|c|}{ FE models } & \multicolumn{3}{|c|}{ collected tests } \\
\hline & $\begin{array}{c}\text { EN 1993-1-4 } \\
{[1]}\end{array}$ & $\begin{array}{c}\text { Gardner and } \\
\text { Theofanous } \\
{[15]}\end{array}$ & $\begin{array}{c}\text { Proposed } \\
\text { Eq. (13) }\end{array}$ & $\begin{array}{c}\text { EN 1993-1-4 } \\
{[1]}\end{array}$ & $\begin{array}{c}\text { Gardner and } \\
\text { Theofanous } \\
{[15]}\end{array}$ & $\begin{array}{c}\text { Proposed } \\
\text { Eq. (13) }\end{array}$ \\
\hline & $\begin{array}{l}\mathrm{N}_{\mathrm{u}, \text { num }} / \\
\mathrm{N}_{\mathrm{u}, \text { pred }}\end{array}$ & $\begin{array}{c}\mathrm{N}_{\mathrm{u}, \text { num }} / \\
\mathrm{N}_{\mathrm{u}, \mathrm{pred}}\end{array}$ & $\begin{array}{l}\mathrm{N}_{\mathrm{u}, \text { num }} / \\
\mathrm{N}_{\mathrm{u}, \text { pred }}\end{array}$ & $\begin{array}{l}\mathrm{N}_{\mathrm{u}, \text { test }} / \\
\mathrm{N}_{\mathrm{u} \text {,pred }}\end{array}$ & $\begin{array}{l}\mathrm{N}_{\mathrm{u}, \text { test }} / \\
\mathrm{N}_{\mathrm{u} \text {,pred }}\end{array}$ & $\begin{array}{l}\mathrm{N}_{\mathrm{u}, \text { test }} / \\
\mathrm{N}_{\mathrm{u} \text {,pred }}\end{array}$ \\
\hline Mean & 1.159 & 1.108 & 1.075 & 1.168 & 1.123 & 1.107 \\
\hline $\mathrm{COV}$ & 0.033 & 0.036 & 0.025 & 0.064 & 0.068 & 0.061 \\
\hline
\end{tabular}




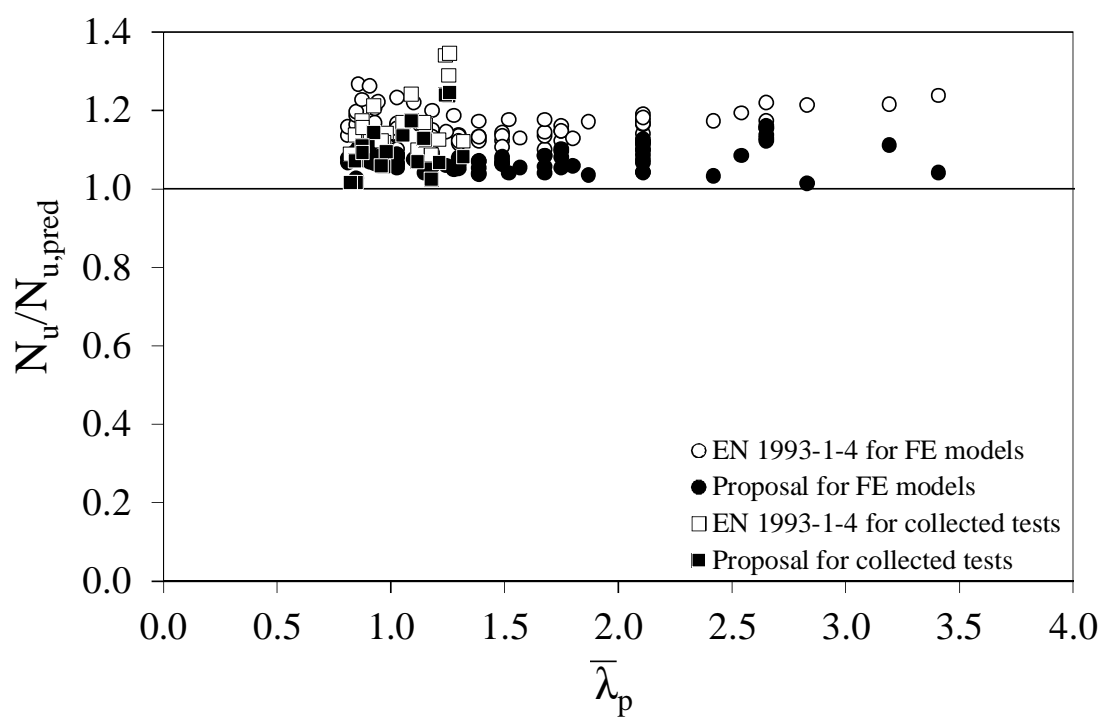

Fig. 13 Comparison between EN 1993-1-4 and proposed effective width equation for collected tests and generated numerical models

\section{Conclusions}

The effects of element interaction on cold-formed ferritic stainless steel sections (SHS and RHS) have been studied herein on the basis of a comprehensive FE model using ABAQUS. Upon benchmarking the FE models against existing tests and having assessed their sensitivity to some key input parameters including material properties and initial local imperfections, parametric studies were performed. The obtained numerical results were used to derive Winter-based equations allowing for the benefits of element interaction effects and to assess various design methods for the treatment of local buckling in ferritic stainless steel crosssection. Two types of design approaches were considered for the assessment: design methods accounting for element interaction effects and those neglecting these effects. The current effective width equation for compressed internal elements given in EN 1993-1-4 [1] and that proposed in Gardner and Theofanous [15], which fall in the latter group, provided conservative results in comparison with the design methods making allowance for the benefits of interaction effects. This included the regression analysis method adapted for austenitic and duplex stainless steel by Theofanous and Gardner [19], the direct strength curves derived by Becque et al. for stainless steel [17] and the effective cross-section method proposed by Zhou et al. for application to high strength steel [20]. The assessment of the applicability of these methods to ferritic stainless steel showed good agreement with the numerical loads achieved in the FE models providing a better representation of the results in comparison with EN 1993-1-4 [1] and [15]. Hence, the effective width equation proposed in [15] was adapted to explicitly capture the benefits of element interaction effects to amend this design method. A new Class 3 slenderness limit equation incorporating those benefits was also set out herein. The proposed design equation was statistically validated and assessed against the loads achieved in the FE models and collected tests from the literature on various stainless steel. The results showed that the proposed design method is applicable to any stainless steel and significantly improves cross-section capacity predictions and reduces scatter, thereby providing a more accurate and cost saving design. For this reason, and in order to further validate the applicability of the proposed design method to all stainless steel on a larger test data basis, further experimental investigation on the structural response of stainless steel slender sections featuring different aspect ratios is required. 


\section{Acknowledgements}

The research leading to these results has received funding from Ministerio de Economía y Competitividad to the Project BIA 2012-36373 "Estudio del comportamiento de estructuras de acero inoxidable ferrítico". The first author would like to acknowledge the financial support provided by the Secretaria d'Universitats i de Recerca del Departament d'Economia i Coneixement de la Generalitat de Catalunya i del Fons Social Europeu to her grant FI-DGR 2012.

\section{References}

[1] EN 1993-1-4. Eurocode 3: Design of steel structures - Part 1-4: General rules Supplementary rules for stainless steels. Brussels: European Committee for Standardization (CEN); 2006.

[2] Gardner L. The use of stainless steel in structures. Progress in Structural Engineering and Materials 2005; 7:45-55.

[3] Baddoo NR. Stainless steel in construction: A review of research, applications, challenges and opportunities. Journal of Constructional Steel Research 2008; 64:1199-06.

[4] Rasmussen KJR, Hancock GJ. Design of cold-formed stainless steel tubular members. I: Columns. Journal of Structural Engineering (ASCE) 1993; 119:2349-67.

[5] Gardner L, Nethercot DA. Experiments on stainless steel hollow sections, Part 1: Material and cross-sectional behaviour. Journal of Constructional Steel Research 2004; 60:1291-18.

[6] Young B, Liu Y. Experimental Investigation of cold-formed stainless steel columns. Journal of Structural Engineering (ASCE) 2003; 129:169-76.

[7] Young B, Lui WM. Behavior of cold-formed high strength stainless steel sections. Journal of Structural Engineering (ASCE) 2005; 131:1738-45.

[8] Gardner L, Talja A and Baddoo NR. Structural design of high-strength austenitic stainless steel. Thin-Walled Structures 2006; 44:517-28.

[9] Theofanous M, Gardner L. Testing and numerical modelling of lean duplex stainless steel hollow section columns. Engineering Structures 2009; 31:3047-58.

[10] Afshan S, Gardner L. Experimental study of cold-formed ferritic stainless steel hollow sections. Journal of Structural Engineering (ASCE) 2013; 139:717-28.

[11] Cashell KA, Baddoo NR. Ferritic stainless steels in structural applications. Thin-Walled Structures 2014; 83:169-81.

[12] Bock M, Real E, Mirambell E. Work package 2: Structural performance of steel members - Report on preliminary FEM study: Local buckling. Report to the RFCS Project Structural applications of ferritic stainless steel (SAFSS). Contract no. RFSR-CT-201000026. Spain: Universitat Politècnica de Catalunya (UPC); 2011. 
[13] Bock M, Gardner L, Real E. Material and local buckling response of ferritic stainless steel sections. Thin-Walled Structures 2015; 89:131-141.

[14] Bock M, Arrayago I, Real E. Experiments on cold-formed ferritic

stainless steel slender sections. Journal of Constructional Steel Research 2015; 109:13-23.

[15] Gardner L, Theofanous M. Discrete and continuous treatment of local buckling in stainless steel elements. Journal of Constructional Steel Research 2008; 64:1207-16.

[16] Schafer BW. Review: the direct strength method of cold-formed steel member design. Journal of Constructional Steel Research 2008; 64:766-78.

[17] Becque J, Lecce M, Rasmussen KJR. The direct strength method for stainless steel compression members. Journal of Constructional Steel Research 2008; 64:1231-38.

[18] Kato B. Rotation capacity of H-section members as determined by local buckling. Journal of Constructional Steel Research 1989; 13:95-109.

[19] Theofanous M, Gardner L. Effect of element interaction and material nonlinearity on the ultimate capacity of stainless steel cross-sections. Steel and Composite Structures 2011; 12:73-92.

[20] Zhou F, Chen Y, Young B. Cold-formed high strength stainless steel cross-sections in compression considering interaction effects of constituent plate elements. Journal of Constructional Steel Research 2013; 80:32-41.

[21] Schardt R. Verallgemeinerte Technische Biegetheorie. Berlin: Springer-Verlag; 1989. German

[22] Davies JM, Leach P. First-order generalised beam theory. Journal of Constructional Steel Research 1994; 31:187-220.

[23] Davies JM, Leach P, Heinz D. Second-order generalised beam theory. Journal of Constructional Steel Research 1994; 31:221-41.

[24] Gonçalves R, Camotim D. GBT local and global buckling analysis of aluminium and stainless steel columns. Computers \& Structures 2004; 82:1473-84.

[25] Abambres M, Camotim D, Silvestre N. GBT-based elastic-plastic post-buckling analysis of stainless steel thin-walled members. Thin-Walled Structures 2014; 83:85-02.

[26] EN 1990. Eurocode - Basis of structural design. Brussels: European Committee for Standardization (CEN); 2006.

[27] Ashraf M, Gardner L, Nethercot DA. Strength enhancement of the corner regions of stainless steel cross-sections. Journal of Constructional Steel Research 2005; 61:37-52.

[28] Cruise RB, Gardner L. Strength enhancements induced during cold forming of stainless steel sections. Journal of Constructional Steel Research 2008; 64:1310-16. 
[29] Gardner L, Nethercot DA. Numerical modeling of stainless steel structural components A consistent approach. Journal of Structural Engineering (ASCE) 2004; 130:1586-01.

[30] Ashraf M, Gardner L, Nethercot DA. Finite element modelling of structural stainless steel cross-sections. Thin-Walled Structures 2006;44:1048-62.

[31] Cruise RB, Gardner L. Residual stress analysis of structural stainless steel sections. Journal of Constructional Steel Research 2008; 64:352-66.

[32] Rasmussen KJR, Burns T, Bezkorovainy P, Bambach MR. Numerical modelling of stainless steel plates in compression. Journal of Constructional Steel Research 2003; 59:134562.

[33] Ellobody E, Young B. Structural performance of cold-formed high strength stainless steel columns. Journal of Constructional Steel Research 2005; 61:1631-49.

[34] Ramberg W, Osgood WR. Description of stress-strain curves by three parameters. Technical note No 902, Washington DC: National advisory committee for aeronautics; 1943.

[35] Mirambell E, Real E. On the calculation of deflections in structural stainless steel beams: an experimental and numerical investigation. Journal of Constructional Steel Research 2000;54:109-33.

[36] Rasmussen KJR. Full-range stress-strain curves for stainless steel alloys. Journal of Constructional Steel Research 2003;59:47-61.

[37] Dawson RG, Walker AC. Post-buckling of geometrically imperfect plates. Journal of the Structural Division 1972;98:75-94.

[38] EN 1993-1-3. Eurocode 3: Design of steel structures - Part 1 - 3: General rules Supplementary rules for cold-formed members and sheeting. Brussels: European Committee for Standardization (CEN); 2006.

[39] EN 1993-1-5. Eurocode 3: Design of steel structures - Part 1 - 5: Plated structural elements. Brussels: European Committee for Standardization (CEN); 2006.

[40] Afshan S, Gardner L. The continuous strength method for structural stainless steel design. Journal of Constructional Steel Research 2013;68:42-49.

[41] Kato B. Deformation Capacity of steel structures. Journal of Constructional Steel Research 1990;17:33-94.

[42] Daali ML, Korol RM. Prediction of local buckling and rotation capacity at maximum moment. Journal of Constructional Steel Research 1995;32:1-13.

[43] Beg D, Hladnik L. Slenderness limit of Class 3 I cross-sections made of high strength steel. Journal of Constructional Steel Research 1996;38:201-17. 
[44] Schafer B, Ádány S. Buckling analysis of cold-formed steel members using CUFSM: conventional and constrained finite strip methods. The 18th international specialty conference on cold-formed steel structures; 2006 Oct; Missouri, USA. p. 39-54.

[45] Seif M, Schafer BW. Local buckling of structural steel shapes. Journal of Constructional Steel Research 2010;66:1232-47.

[46] AISI S100-12. North American Specification for the design of cold-formed steel structural members. Washington, D.C: American Iron and Steel Institute; 2012.

[47] AS/NZS 4600. Cold-formed steel structures. Sydney, Australia: Standards Australia; 2005.

[48] Davaine L. Formulations de la résistance au lancement d'une âme métallique de pont raidie longitudinalement - Résistance dite de "Patch Loading" [dissertation]. France: L’Institut National des Sciences Appliquées de Rennes; 2005. French.

[49] Bock M, Mirada FX and Real E. Statistical evaluation of a new resistance model for cold-formed stainless steel cross-sections subjected to web crippling. International Journal of steel structures 2015;15:227-244.

[50] Afshan S, Francis P, Baddoo N. R, Gardner, L. (submitted). Reliability analysis of structural stainless steel design provisions. Journal of Constructional Steel Research. 